\title{
Factors in implementation of clinical commissioning policy in improving health and wellbeing and/or reducing health inequalities in the English NHS: a systematic review of the evidence
}

Krishna Regmi ( $\nabla$ krishna.r.regmi@gmail.com )

Institute for Health Research, University of Bedfordshire, University Square, Luton, Bedfordshire LU1 3JU, UK https://orcid.org/0000-0002-1408-1978

Oliver Mudyarabikwa

Faculty of Health and Life Sciences, Coventry University, Richard Crossman Building, Room RC145, Priory Street, Coventry, CV1 5FB

\section{Systematic Review}

Keywords: GP commissioning, population health, health inequalities, NHS, systematic review

DOI: https://doi.org/10.21203/rs.3.rs-37640/v1

License: (c) (1) This work is licensed under a Creative Commons Attribution 4.0 International License. Read Full License 


\section{Abstract}

Objective: This study aimed to identify and synthesise the factors in implementing clinical commissioning policy in improving health and/or reducing health inequalities in the English NHS.

Methods: Systematic review was conducted. We searched Medline, EMBASE, CINAHL, Allied \& Complementary Medicine, DH-DATA, Global Health and CINAHL for primary studies that assessed the enablers and barriers, and reported in accordance with PRISMA statement. Methodological quality was appraised using JBI Critical Appraisal tools and Mixed Methods Appraisal Tool [MMAT] to assess the methodological qualities, and synthesised performing thematic analysis. Two reviewers independently screened the papers and extracted data.

Results: We included six primary studies (including a total of 1155 participants) in the final review. The studies reported two broad categories, under four separate themes: agenda of health inequalities not fully addressed; poor evidence for reducing health inequalities; reform through restructuring of organisations, and strategic approaches.

Conclusion: This study provides useful factors - enablers and barriers - to implement and deliver clinical commissioning policy in improving health and wellbeing. These factors could be assessed in future to develop objective measures and interventions to establish the link between commissioning and health inequalities improving equitable access, health outcomes and effective partnerships.

\section{Introduction}

Since the establishment of the English National Health Service (NHS) in 1948, several organisational changes have been made, equally influenced by the components of commissioning and health inequalities. ${ }^{1}$ Commissioning is an approach to moving services from hospital to community settings, to avoid potential cases of emergency admissions as admissions trends have risen, ${ }^{2-4}$ as well as reduced health inequalities that may impact positively on the social determinants of health. ${ }^{5(\mathrm{p} .5)}$ In the NHS, commissioning is more about health planning or strategic

purchasing. ${ }^{6}$

Over the past 30 years, different strategies have been implemented to tackle health inequalities, mainly focusing on "improving the health of the most deprived groups, and narrowing the gap or universal health improvements" 7,8 but these issues have not been successfully and appropriately addressed. Still the impact of health inequalities is very alarming. For example, it was estimated that the least advantaged, compared to the most advantaged, would otherwise have enjoyed, 1.3 and $2.5 \mathrm{~m}$ extra years of life. ${ }^{9,10}$ Marmot's work on health inequalities concludes that, despite general improvements in health, still a clear gradient appeared, such that people living in the poorest neighbourhoods, will, on average, die seven years earlier than people living in the richest neighbourhoods. ${ }^{11(p .10)}$ 
Recently the most extensive NHS reform has taken place in England with the implementation of the Health and Social Care Act 2012. This Act not only abolishes primary care trusts and decentralises the decision-making process, including public health functions and resources to newly-formed clinical commissioning groups (CCGs), also called general practitioners' (GPs) lead or clinical commissioning (CC) ${ }^{12}$ but also clearly recognised the first legal duties of NHS to improve service quality and reduce inequalities between persons by creating the provision of healthcare for all. ${ }^{13-15}$

The performance of commissioning varies. For example, despite serving the most deprived communities, Liverpool, City and Hackney in London, Fareham and Gosport, East Surrey, Crawley and the Isle of Wight CCGs appeared as worst performers, whereas Tower Hamlets and Portsmouth CCGs appeared on the best performers list. Similarly, South Cheshire, Manchester, Blackburn, Darwen and Islington performed badly on inequalities, while East Surrey CCG did well while serving wealthy communities, using emergency admissions as an indicator, i.e. how well the NHS is succeeding in delivering out-of-hospital services to deprived patients with complex long-term conditions. ${ }^{16} \mathrm{~A}$ preliminary scan shows some empirical research on health inequalities in UK settings, ${ }^{9,11}$ but the literature has never been systematically reviewed or synthesised focusing on the role of healthcare in reducing health inequalities. ${ }^{17-20}$ Second, some related reviews have reported benefits ${ }^{4,17,21-23}$ as well as challenges of commissioning. ${ }^{22,24-29}$ No systematic reviews have been published looking at these effects. This review aims to identify and synthesise the factors to implementing clinical commissioning policy in improving health and/or reducing health inequalities in the English NHS.

\section{Methods}

This study utilised a systemic review design which involves "collating all empirical evidence that fits prespecified eligibility criteria in order to answer a specific research question." 30,31

\section{Criteria for considering studies for review}

Inclusion criteria

1. Type of studies: Primary research describing the clinical commissioning or GP-led commissioning of primary care and health inequalities, healthcare inequalities or healthcare disparities across all age groups in NHS England.

2. Research reporting enablers and barriers to implementing clinical commissioning or GP-led commissioning and healthcare inequalities or healthcare disparities as outcome measures.

3. Published articles using quantitative (e.g. cross-sectional, randomised controlled trials, cohort, casecontrol) or qualitative (ethnography, grounded theory, phenomenological studies), if published in peer-reviewed journals.

4. Articles published in English, from 2012 to 2020.

Exclusion criteria 
1. Articles published in narrative review, opinion pieces, letters and any other publications lacking primary data including grey literatures.

2. Studies deemed to have overall poor quality.

\section{Search strategy}

A broad search strategy has been designed to maximise the level of sensitivity and specificity in searching, ${ }^{32}$ and improve both recall ratio and precision ratio. ${ }^{33}$ Medical subject heading (MeSH) and free terms to focus and broaden our search results appropriately for commissioning and health inequalities were used in the main search combined with the UK filter developed by Ayiku et al. ${ }^{34}$ A detailed SR protocol with specific search terms has been developed by authors, and provided in Additional file 1 .

\section{Study selection strategy}

All studies emerging from the databases have been screened twice: first, screening of abstracts and titles against minimum inclusion criteria. Second, review of full text of the studies. The standard PRISMA flow diagram was used to provide the process of study selection ${ }^{35}$ (Fig. 1).

\section{Quality appraisal of included studies}

Methodological quality was appraised using JBI Critical Appraisal tools ${ }^{36,37}$ and Mixed Methods Appraisal Tool [MMAT] ${ }^{38}$ to assess the methodological qualities. These tools have established content validity and have been piloted across all methodologies. ${ }^{39-41}$ The retrieved papers were assessed by two reviewers (KR and OM) using the standardized 10-item, 9-item and 5-item critical appraisal checklists for qualitative assessment, quantitative and mixed methods studies, respectively. To facilitate comparison of appraisal processes, both reviewers recorded the rationale for inclusion or exclusion, and discrepancies were discussed and resolved by consensus. Table 1 presents the results from the critical appraisal.

Table 1 Results from the critical appraisal of methodological quality 
sults from critical appraisal of four qualitative studies - JBI Critical Appraisal Checklist for Qualitative search ${ }^{36}$

\begin{tabular}{|c|c|c|c|c|c|c|c|c|c|c|}
\hline $\begin{array}{l}\text { dies } \\
\text { Que } \\
\text {,n }\end{array}$ & 1 & 2 & 3 & 4 & 5 & 6 & 7 & 8 & 9 & 10 \\
\hline $\begin{array}{l}\text { Der } \\
\text { tt et } \\
: 6\end{array}$ & $N o$ & Yes & Yes & Yes & Yes & $\mathrm{No}$ & No & Yes & Yes & Yes \\
\hline $\begin{array}{l}\text { ner } \\
\text { al. }{ }^{47}\end{array}$ & $N O$ & Yes & Yes & Yes & Yes & $\begin{array}{l}\text { Unclea } \\
r\end{array}$ & Yes & Yes & Yes & Yes \\
\hline $\begin{array}{l}\text { seth } \\
\text { et } \\
88\end{array}$ & Yes & Yes & Yes & Yes & Yes & $N o$ & No & Yes & Yes & Yes \\
\hline $\begin{array}{l}\text { way } \\
\text { al. }{ }^{49}\end{array}$ & Yes & Yes & Yes & Yes & Yes & $N o$ & $N o$ & Yes & Yes & Yes \\
\hline otal & $2 / 4$ & $4 / 4$ & $4 / 4$ & $4 / 4$ & $4 / 4$ & 0 & $1 / 4$ & $4 / 4$ & $4 / 4$ & $4 / 4$ \\
\hline
\end{tabular}

sults from critical appraisal one quantitative study - JBI Critical Appraisal Checklist for Studies Reporting :valence Data ${ }^{37}$

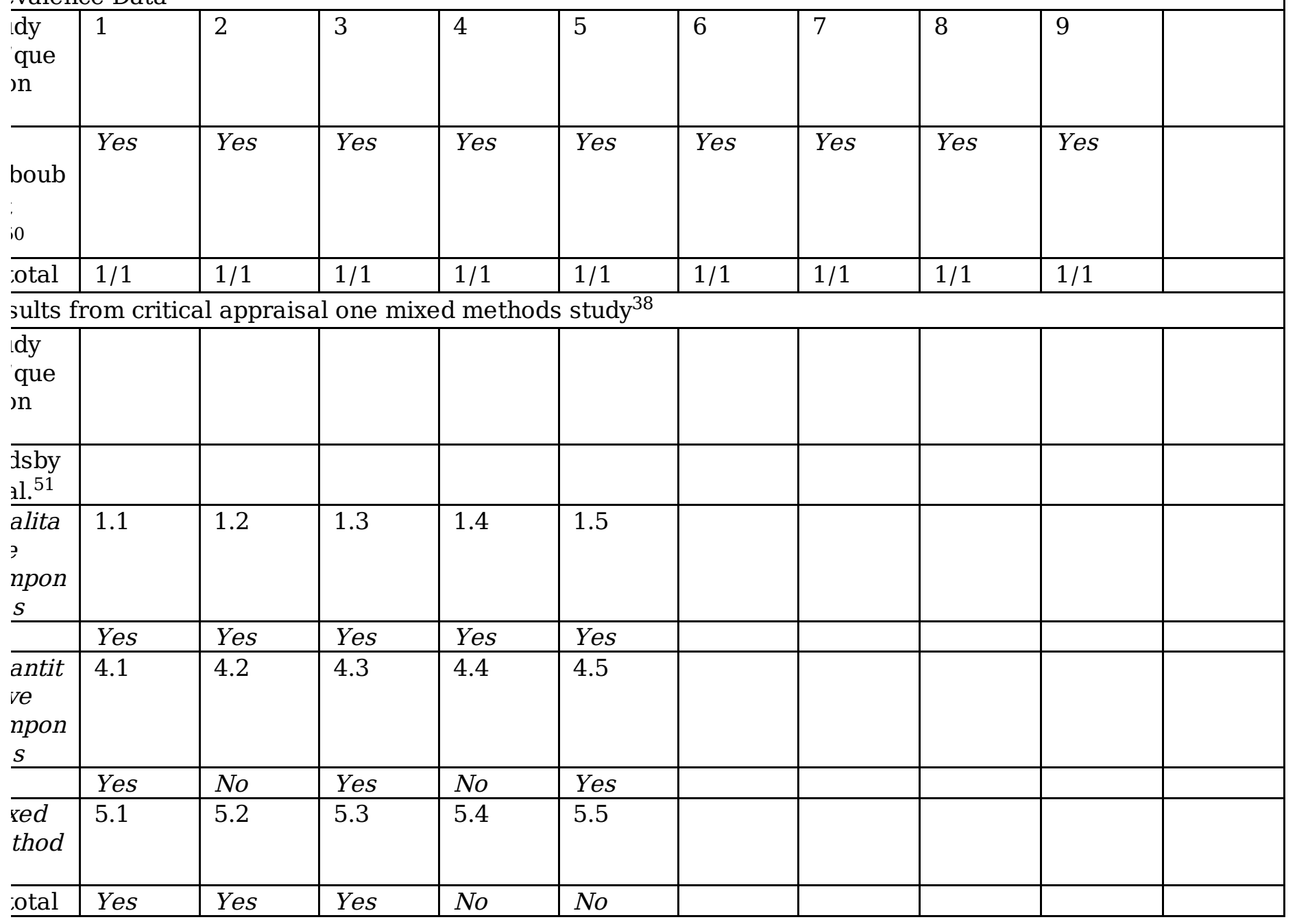

\section{Data analysis and synthesis}

Studies in this review were not sufficiently homogenous to analyse using meta-analysis. ${ }^{42}$ Therefore, results are summarised using qualitative narrative synthesis and tabular form. ${ }^{43,44}$ As Joff ${ }^{45}$ suggests, 
we examined these themes and sub-themes on "their similarities, differences and contradictions", to be able to address the research question about potential barriers (challenges) and facilitators (benefits) of clinical commissioning on reducing health inequalities. Coding process and the development of themes throughout the analysis were discussed among authors.

\section{Results}

The search results are summarised in Figure 1. We identified 2166 references, scanned 133 titles and abstracts and retrieved 42 publications for full texts. From these, we included six studies (including a total of 1155 participants) that reported data on clinical commissioning and health inequalities ${ }^{46-51}$ and excluded 36 studies (Additional file 2). Of the six, four were qualitative. ${ }^{46-49}$ All studies were conducted between 2010 and 2017 and the list of included studies is presented in Table 2.

Table 2 Summary of reviewed studies 


\begin{tabular}{|c|c|c|c|c|c|}
\hline hor & $\begin{array}{l}\text { Aims/study } \\
\text { question }\end{array}$ & $\begin{array}{l}\text { Study type and } \\
\text { method }\end{array}$ & Dates & Participants & Key findings \\
\hline $\begin{array}{l}\text { Dermott et } \\
: 6\end{array}$ & $\begin{array}{l}\text { To analyse } \\
\text { how CCGs - Q } \\
\text { have } \\
\text { responded to ap } \\
\text { the new } \\
\text { responsibility } \\
\text { and to identify } \\
\text { challenges anha } \\
\text { factors that su } \\
\text { facilitated or } \\
\text { inhibited } \\
\text { achievement } \\
\text { of integrated } \\
\text { care systems }\end{array}$ & $\begin{array}{l}\text { alitative - } \\
\text { loratory } \\
\text { proach } \\
\text { ta were } \\
\text { lected using } \\
\text { erviews and } \\
\text { ional telephone } \\
\text { veys }\end{array}$ & $2015-2017$ & 112 & $\begin{array}{l}\text { Integration of } \\
\text { budgets and } \\
\text { commissioning } \\
\text { responsibilities } \\
\text {; CCGs } \\
\text { understood the } \\
\text { roles of } \\
\text { primary and } \\
\text { local needs, } \\
\text { new models of } \\
\text { care }\end{array}$ \\
\hline ner et al. ${ }^{47}$ & $\begin{array}{lr}\text { To inform } \\
\text { current } \\
\text { debates by } \\
\text { reporting } \\
\text { findings from ad } \\
\text { series of in- } \\
\text { depth se } \\
\text { interviews int } \\
\text { conducted with } \\
\text { a range of } \\
\text { experienced } \\
\text { professionals } \\
\text { working in } \\
\text { varied roles } \\
\text { within the } \\
\text { health and } \\
\text { social care } \\
\text { commissioning } \\
\text { arena }\end{array}$ & $\begin{array}{l}\text { alitative } \\
\text { thods } \\
\text { ta were } \\
\text { lected using } \\
\text { ni-structured } \\
\text { in-depth } \\
\text { erviews }\end{array}$ & 2012 & 42 & $\begin{array}{l}\text { Community did } \\
\text { not feel any } \\
\text { progress on } \\
\text { the issue } \\
\text { of health } \\
\text { inequalities } \\
\text { but reported } \\
\text { better } \\
\text { management } \\
\text { due to } \\
\text { partnership, } \\
\text { commitment } \\
\text { and strategic } \\
\text { programme } \\
\text { approach }\end{array}$ \\
\hline $\begin{array}{l}\text { eetham et } \\
8\end{array}$ & $\begin{array}{l}\text { To examine } \\
\text { the factors } \\
\text { affecting the } \\
\text { design, } \\
\text { commissioning } \\
\text { and delivery of } \\
\text { integrated } \\
\text { health and } \\
\text { wellbeing } \\
\text { services } \\
\text { (IHWSs), } \\
\text { which seek to } \\
\text { address } \\
\text { multiple } \\
\text { health-related } \\
\text { behaviours, } \\
\text { improve }\end{array}$ & $\begin{array}{l}\text { alitative } \\
\text { thods } \\
\text { mi-structured } \\
\text { erviews and } \\
\text { luation were } \\
\text { lducted to } \\
\text { lect data }\end{array}$ & $2015-2016$ & 16 & $\begin{array}{l}\text { Challenging } \\
\text { organisational } \\
\text { context but } \\
\text { realised long- } \\
\text { term benefits } \\
\text { to population } \\
\text { health and } \\
\text { wellbeing }\end{array}$ \\
\hline
\end{tabular}




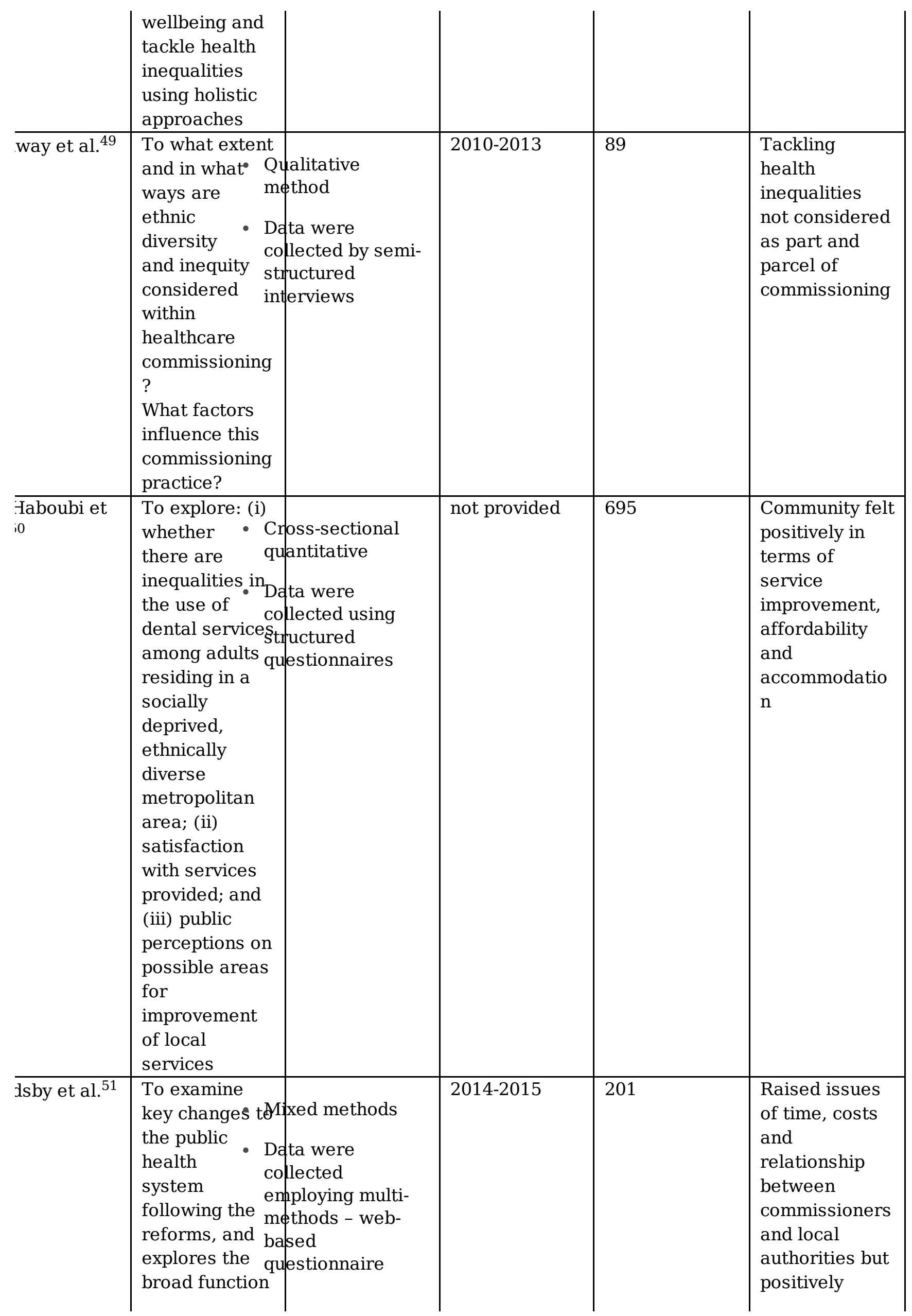




\begin{tabular}{l|l|l}
$\begin{array}{l}\text { of } \\
\text { commissioninglepth case studies } \\
\text { for health } \\
\text { improvement } \\
\text { within the new } \\
\text { system }\end{array}$ & & $\begin{array}{l}\text { influenced the } \\
\text { prioritisation }\end{array}$ \\
\end{tabular}

Synthesis of evidence

This study is organised under four major themes/findings which emerged.

Finding 1: An overwhelming majority (5 of 6 papers, 83\%) of the papers indicated the agenda of health inequalities has not given priority by clinical commissioning

The primary and overriding finding of this study is that clinical commissioning (CC) has not given health inequalities as a priority agenda of the commissioning process. Some evidence indicated that CC was more considered a public health activity to determine health needs of individuals or populations by identifying, assessing and prioritising their needs and actions as general public health functions rather than commitment to reducing health inequalities. ${ }^{46}$ One paper, however, reported that $\mathrm{CC}$ has been used as a tool to improve service improvements to address inequalities. ${ }^{47}$ Participants expressed these aspects thus:

Commissioning was considered as one of the broad aspects of public health activity [...] identifying needs, reviewing service provision, deciding priorities, procuring services, and managing performance. ${ }^{51}$

Responsibility for the health inequalities agenda was seen primarily as a function of public health roles rather than part and parcel of core healthcare commissioning work, even where PCTs had adopted explicit strategic priorities relating to inequalities. ${ }^{47}$

CCGs understand primary care and local needs. Allowing CCGs to commission primary care alongside other services would support the development and implementation of local strategies for service improvement, support innovation in primary care and allow investment in primary care (by allowing resource shifting). ${ }^{46}$

Finding 2: More than half (4 of 6, 67\%) of the papers reported reform through restructuring and organisations, and strategic approaches in collaboration, commitments and engagement as benefits of commissioning in healthcare.

The benefits of clinical commissioning have been reported across different studies. Based on further analysis of the papers, three major benefits emerged:

a) Context and restructure of services: Since the Health and Social Care Act (HSCA2012), the commissioning process has been much better in terms of understanding the wider social-political context 
of local healthcare, recognising wider consultation on decision-making to plan and deliver health services involving local elected people and organisations. Similarly, this reform has relocated public health from NHS to local government, and prepared staff for transition to deliver integrated approaches. ${ }^{51(p .4)}$ The following extracts illustrate issues relating to service context and restructure:

The relocation of public health from the NHS to local government provided important context for the introduction of IHWSs. Participants in both sites felt there were new opportunities to work across local authority directorates to address the wider determinants of health and health inequalities. ${ }^{48}$

There is wider consultation on decisions in the local council setting than in the NHS, and elected members now have a strong influence on public health prioritisation. There is more (and different) scrutiny being applied to public health contracts, and most councils have embarked on wide-ranging changes to the health improvement services they commission. Public health money is being used in different ways as councils are adapting to increasing financial constraint. ${ }^{51}$

b) Strategic approaches - service integration and commitment. CC offers greater knowledge and understanding of integrating local health services reflecting data to local health plans. McDermott et al. ${ }^{46}$ (p.7) further add that "Integrated care [in the context of $\mathrm{CC}$ ] requires detailed local work to build trust and develop context-specific mechanisms to work across boundaries." Similarly, a great commitment through investment has been given within council services to improve public health to meet needs and expectations. Included papers reported these aspects as follows:

Potential for greater integration of knowledge and data on local communities, stronger JSNAs and better understanding of needs, was noted with the move of public health to Local Authorities. In addition, new structures, particularly the HWBB, created the possibility of new opportunities for representation. ${ }^{47}$

Greater recognition of public health objectives and expected outcomes in a wider range of council services as a result of public health investment. And we saw public health staff working hard to influence the wider workforce. ${ }^{51}$

Both local authorities had a long-term strategic commitment to community development and asset-based approaches, which was seen as beneficial by public health commissioners. ${ }^{48}$

c) Partnership and engagement. The association between CC and wider healthcare partnership and engagement has been reported positively in terms of meeting healthcare needs by reducing duplication costs/resources and sharing knowledge and expertise. These studies conveyed this view:

Expressed concerns that CCGs would have to start a lot of community engagement work from scratch, and develop meaningful relationships with key communities. Engagement was seen by many participants to be important not just for understanding population needs, but also in commissioning services that effectively meet those needs. ${ }^{47}$ 
...recognised and articulated the potential added value of collaborative working between NHS and local authority partners, plus the third sector in WFL. Anticipated benefits included reducing duplication, extending the reach of existing services and programmes, sharing expertise and capacity and maximising opportunities for innovation. The idea of offering a more streamlined accessible approach, which seeks to knit together a number of different functions was broadly welcomed. ${ }^{48}$

GPC endorsement of the social model of health underpinning LWG and WFL, there was also broad acceptance of prevention and early intervention, recognised as being more cost-effective than long-term treatment. ${ }^{48}$

\section{Finding 3: All six papers (100\%) indicated that there was some poor evidence for reducing health inequalities through the clinical commissioning process, primarily due to poor approaches utilised in decision-making, lack of budgets, time, strategic priorities, and poor commitments.}

These barriers have been broadly categorised into two levels:

a) Structural impediments: all papers reported that in commissioning, the decision-making process was a challenge as it demanded wider consultation with a range of policy-planners, politicians, and decisionmakers at local levels. Similarly, studies reported commissioning responsibilities have been fragmented between different organisations (NHS England, PHE, local councils and CCGs), and co-ordination was slow, difficult and bureaucratic. ${ }^{48,51}$ Therefore, there was serious concern raised not only about diluting local authorities' action on health inequalities but also failing to recognise and reduce health inequalities because of poor direction from central government and poor commissioner engagement in health services commissioning. ${ }^{47,49}$ The extracts below illustrate this:

Decision-making within councils was found to be very different to that within PCTs. Decision-making across the local system following the reforms was intended to be more co-ordinated. However, with commissioning responsibilities now fragmented between NHS England, PHE, local councils and CCGs, our research found that co-ordination was proving to be difficult. ${ }^{51}$

Local councils received their public health staff, resources and duties at a time of unprecedented cuts to their budgets. ${ }^{16}$ These cuts precipitated ongoing restructures within councils to streamline their organisations and reduce staffing costs. The positioning of public health teams within councils varied. ${ }^{51}$

Poor track record of shifting resources out of secondary care and into the types of primary care and public health interventions felt to be capable of achieving a significant impact on health inequalities. ${ }^{47}$

b) Personal impediments. More than half of the papers reported personal impediments ( 3 of $6,60 \%)$ to reducing health inequalities in the CC process. Commissioners' inadequate level of knowledge and expertise, poor trust/relationships between local authorities and staff involved in the commissioning process, poor partnership, working in different geographical locations and engagement, and a largely pessimistic approach have been reported as major challenges. ${ }^{47}$ Some extracts below illustrate this: 
Most commissioners did not view identifying and tackling ethnic inequalities in healthcare access, experience or outcomes as part-and-parcel of their job due to lack of clarity about their responsibilities. ${ }^{51}$

There was much confusion over where staff should be transferred to (sometimes depending on the proportion of their time spent on service commissioning versus service provision), and around the organisation of budgets. There were instances where this tested relationships between councils and CCGs. ${ }^{51}$

Similarly,Pressures to get both services 'off the ground' quickly, coupled with different organisational cultures, a history of competing for contracts and mistrust arising from short-term contracts and reducing budgets, may have destabilised early efforts to build relationships among staff and with communities. ${ }^{48}$

\section{Finding 4: Most papers (4 of 6 papers, 67\%) indicated improving health services, appropriate policy and approaches should be in practice}

These studies reported service improvement associated with availability, affordability, and accommodation or flexibility of services. ${ }^{50}$ Similarly, organisational contexts, appropriate translating of evidence into practice, were factors reported that influence health services locally improving. The extracts below highlight some relevant issues:

Staff, costs, and opening hours were the commonest areas where participants made recommendations for improvements to local dental services. ${ }^{50}$

Greater accountability of healthcare commissioners to the public and more influential needs assessments via emergent Health \& Wellbeing Boards. ${ }^{47}$

Investment and opportunities contained in national and local initiatives were seen as major contributors to enabling CCGs achieving a people-centred, locally driven,integrated primary care service with general practice. ${ }^{46}$

Fig. 2 is a conceptual framework (CF) that emerged from this study, noting that making the commissioning is a continuous assessment process. To make the effective link between $\mathrm{CC}$ and reducing health inequalities, this will give a stronger link between public health and broader work on the social determinants of health; putting people at the centre of the framework ensures their needs are appropriately met by providing best-quality care in primary care services. The approach would also give more immediate results in improving public health, making it part of the local political landscape. ${ }^{52}$ It is therefore important to routinely monitor the inequalities in access and health outcomes. This CF also acknowledges the skills and capacities of GPs and other healthcare providers in leadership and governance, and ensures they can fulfil their operational and strategic roles. ${ }^{53,54}$

\section{Discussion}


This study was undertaken to synthesise the evidence in relation to $\mathrm{CC}$ and health inequalities, as there is a rich heritage of addressing health inequalities within the NHS. The study reported clear gaps due to different commissioning structures, different roles, financial pressures, accountabilities, responsibilities, GP skills and competencies, organisation experience and local contextual conditions, to address inequalities in policy and practice. ${ }^{46,55}$ Our study identified different facilitators and barriers (Table 3), clearly aligned with the Marmot health inequalities review, stating that health inequalities are determined by a complex mixture of factors. Access to healthcare was one of the pillars, and other were the wider determinants of health, e.g. income, housing, education, employment, lifestyles. ${ }^{11}$ Marmot ${ }^{11}$ also argued that "addressing health inequalities at earlier stages of life was the surest way to reduce the long-term incidence of health inequalities". NHS also reported that "reducing health inequalities improves life expectancy and reduces disability across the social gradient. Tackling health inequalities is therefore core to improve access to services, health outcomes, improving the quality of services and the experiences of people."14(p.11)

Table 3 Enablers and barriers to clinical commissioning and the contribution of each study 


\begin{tabular}{|c|c|c|c|c|c|c|}
\hline sme & $\begin{array}{l}\text { McDermott } \\
\text { et al. }{ }^{46}\end{array}$ & $\begin{array}{l}\text { Turner et } \\
\text { al. }^{47}\end{array}$ & $\begin{array}{l}\text { Cheetham } \\
\text { et al. }{ }^{48}\end{array}$ & $\begin{array}{l}\text { Salway et } \\
\text { al. }^{49}\end{array}$ & $\begin{array}{l}\text { Al-Haboubi } \\
\text { et al. } 50\end{array}$ & $\begin{array}{l}\text { Gadsby et } \\
\text { al. }{ }^{51}\end{array}$ \\
\hline $\begin{array}{l}\text { es and } \\
\text { formanc }\end{array}$ & 1 & & 1 & & & $\mathrm{~m}$ \\
\hline sl / data & & $£$ & & & & \\
\hline nicity & & & & l & l & \\
\hline isfaction & & & & & $\mathrm{m}$ & \\
\hline $\begin{array}{l}\text { ial } \\
\text { de }\end{array}$ & & & & & l & \\
\hline $\begin{array}{l}\text { at } \\
\text { ategic } \\
\text { ds } \\
\text { essment }\end{array}$ & $\mathrm{m}$ & $\mathrm{m}$ & & & & \\
\hline $\begin{array}{l}\text { ority } \\
\text { ting }\end{array}$ & & $\mathrm{m}$ & & & & \\
\hline atext & $\mathrm{m}$ & & $\mathrm{m}$ & & & $\mathrm{m}$ \\
\hline $\begin{array}{l}\text { yanisatio } \\
\text { nd } \\
\text { dcture }\end{array}$ & $\mathrm{m}$ & & $£$ & & & $\mathrm{~m}$ \\
\hline $\begin{array}{l}\text { ler } \\
\text { erminant } \\
\text { f health }\end{array}$ & & & $\mathrm{m}$ & & & \\
\hline $\begin{array}{l}\text { igmented } \\
\text { l split }\end{array}$ & & & 1 & & & 1 \\
\hline $\begin{array}{l}\text { ancial } \\
\text { ts } \\
\text { l public } \\
\text { llth } \\
\text { lgets } \\
\end{array}$ & 1 & & 1 & l & 1 & 1 \\
\hline $\begin{array}{l}\text { ange } \\
\text { nagemen }\end{array}$ & & & $\mathrm{m}$ & & & \\
\hline nplexity & 1 & & & & & 1 \\
\hline $\begin{array}{l}\text { logue } \\
\text { ween } \\
\text { nmission } \\
\text { and } \\
\text { viders }\end{array}$ & $\mathrm{m}$ & & $\mathrm{m}$ & & & \\
\hline nmitmen & l & l & $\mathrm{m}$ & & & \\
\hline $\begin{array}{l}\text { aring and } \\
\text { jagement }\end{array}$ & $\mathrm{m}$ & 1 & & & & $\mathrm{~m}$ \\
\hline $\begin{array}{l}\text { laborativ } \\
\text { tnership } \\
\text { jagement }\end{array}$ & & $£$ & $\mathrm{~m}$ & & & \\
\hline :vention & & & $\mathrm{m}$ & & & \\
\hline
\end{tabular}




\begin{tabular}{|c|c|c|c|c|c|c|}
\hline $\begin{array}{l}\text { l early } \\
\text { srvention }\end{array}$ & & & & & & \\
\hline $\begin{array}{l}\text { ision- } \\
\text { king }\end{array}$ & & & & & & $£$ \\
\hline $\begin{array}{l}\text { alth } \\
\text { dity and } \\
\text { quality }\end{array}$ & $\mathrm{l}$ & $£$ & $\mathrm{l}$ & $\mathrm{l}$ & l & \\
\hline $\begin{array}{l}\text { isimistic } \\
\text { jroach }\end{array}$ & & l & & & & \\
\hline oritisatio & & & & & & $\mathrm{m}$ \\
\hline $\begin{array}{l}\text { orove } \\
\text { vices }\end{array}$ & $\mathrm{m}$ & & & $\mathrm{m}$ & $\mathrm{m}$ & $\mathrm{m}$ \\
\hline $\begin{array}{l}\text { tracts } \\
\text { l } \\
\text { endering }\end{array}$ & $\mathrm{l}$ & & 1 & & & $\mathrm{l}$ \\
\hline iticised & & & $\mathrm{l}$ & & & \\
\hline $\begin{array}{l}\text { certainty } \\
\text { l delays }\end{array}$ & & & 1 & & & \\
\hline $\begin{array}{l}\text { ationship } \\
\text { nd } \\
\text { ponsibilit } \\
\text { between } \\
\text { Incils and } \\
\text { Gs }\end{array}$ & $\mathrm{m}$ & & $£$ & & & l \\
\hline $\begin{array}{l}\text { act at a } \\
\text { al level }\end{array}$ & 1 & & $\mathrm{l}$ & & $\mathrm{m}$ & \\
\hline $\begin{array}{l}\text { mment } \\
\mathrm{h} \text { the } \\
\text { ategic } \\
\text { srities of } \\
\text { vention } \\
\text { l early } \\
\text { srvention }\end{array}$ & $\mathrm{m}$ & & $\mathrm{m}$ & $\mathrm{m}$ & $\mathrm{m}$ & \\
\hline
\end{tabular}

$\mathrm{m}$ facilitator; 1 barrier; $€$ facilitator and barrier.

Due to implementation of $\mathrm{CC}$, this study has revealed holistic, targeted and integrated approaches which are clearly beneficial to reduce health/social inequalities. It is because the remit of commissioning involves assessment of local needs as well as deciding priorities and strategies and purchasing services for local populations - strategic purchasing. ${ }^{46,56}$

$\mathrm{CC}$ has been viewed as a new and integrated model of care holding promise for addressing inequalities largely at the provider:patient interface. ${ }^{57,58}$ We also argued that through CC, it is not just about having enough GPs, but also whether they listen to the whole community. ${ }^{58}$ 
Our study also found that power and decisions have been shared with communities and service providers, but still there are some gaps or challenges in terms of transformation of funds and availability of funds to run community services and their priorities are structured differently. ${ }^{59}$ Therefore, changing culture of communities from passive consumers to active partners would be one of many options to make wider access to healthcare possible. ${ }^{58}$ Atkins et al.'s finding in this context might be useful because they suggest that we: "should work more clearly with local government public health team to define research questions [issues] through the lenses of local government and their proprieties and imperatives, taking into account the context of the significant loss of resources local government are dealing with." ${ }^{60, p .15}$

Similarly, in CCGs changing responsibilities means these two partners [health services and local government] have to think afresh about the away they address these issues and of course, things like devaluation e.g. CC give us a new opportunity to look at this. ${ }^{61}$ This clearly aligns with the findings of Baroness Thornton and colleagues showing that NHS can do things to help tackle inequality addressing the social determinants of health and the wider factors. ${ }^{58}$ Moran et al.'s survey of over 2600 GPs, claimed that though approximately $30 \%$ of the GPs agreed that commissioning was part of their role and responsibilities, most of them also agreed that their involvement would add value to the commissioning process in terms of influence and address the local healthcare needs. ${ }^{59}$

NHS Commissioning Board ${ }^{13}$ complements existing research claiming that "clinical leadership would significantly improve their performance in their practices" in the NHS. Clinical leadership is, therefore, considered "central to all models of primary care-led commissioning", involving both the components of service improvement and service redesign. ${ }^{46,62}$ In fact, such interpretations are supported by earlier work, ${ }^{13,14}$ i.e. effective GP engagement to take on a greater level of responsibility in the commissioning of primary care services would be an important role, as reported by our own study.

Williamson ${ }^{63}$ supports this view, stating that better understanding of health needs and gaps, we can create some effective service models and care pathways. Similarly, this study also supports Smith et al. emphasising that: "competent commissioning may help ensure appropriate monitoring and review of current services, the design and planning of necessary changes, and setting of priorities for funding". ${ }^{5(p .12)}$ Another study conducted by Atkins et al. among public heath directors and healthcare practitioners acknowledged that they need to develop service commissioning skills. ${ }^{60}$

This study has further highlighted that one of the challenges GPs faced was due to poorly defining their roles in clinical commissioning, as well as the size of population they should cover ${ }^{64}$ Similarly, frustration at work among GPs, mainly due to increased volume of work and lack of resources, have been reported as major barriers since the implementation of HSCAct12 which has also been reported in Humphery and Claver's findings. ${ }^{65}$ Working in collaboration with a wide range of stakeholders would help develop appropriate local healthcare strategies and evidence-inform policy in practice. ${ }^{60,66}$ Unequal distribution of funds between the primary and secondary care resulting in inefficiencies and poor 
performance have also been reported as other barriers. As reported in the previous study, ${ }^{67}$ we also found some limited attention to ethnic diversity and inequality within healthcare commissioning. From the users' perspective, our study has reported that users' demand and expectations in line with the demographic changes would certainly influence GPs' ability in terms of (re)designing and (re)shaping primary healthcare services at the local level, as highlighted in other similar studies. ${ }^{65,68-71}$ Therefore, as Checkland et al. ${ }^{64}$ suggested, it is important to support the development of new models of service provision and work more closely with LAs, other providers (e.g. voluntary sector) and other local bodies (e.g. health and wellbeing boards) for commissioning of primary care services.

\section{Strengths and limitations of the review}

To our knowledge, this review might be the first systematic review to examine the factors - enablers and barriers - since the implementation of $\mathrm{CC}$ for improving health quality and reducing health inequalities in the English NHS. This review was conducted using a comprehensive search strategy developing a systematic review research protocol. $\mathrm{DH}^{72,73}$ and NHS Improvement ${ }^{74}$ proposed some commissioning cycles, but how a commissioning model would be meaningful in addressing health inequalities has not been reported before. This study has proposed a CF embedding input-process-outcome (IPO) configuration, putting users at the centre of the process in terms of bringing positive outcomes in improving quality care, mitigating possible barriers and enhancing enablers or facilities (Fig. 2), and also highlighting enablers and barriers to clinical commissioning and each study contribution (Table 3).

This review has, however, a number of limitations. First, the potential limitation of this study is that as this study was not externally funded, and therefore time and resource were constrained, we were unable to include and review grey literatures. Second, studies are variable in sample size, quality and population, which are open to bias, and also due to the heterogeneity of data, it precludes a meaningful metaanalysis to measure the impact of specific enablers or barriers, therefore the findings warrant generalisation. Third, despite overall good methodological quality of the included papers, some studies provided inadequate descriptions of study methods and procedures. ${ }^{46,47,51}$ Fourth, as Maden ${ }^{75}$ reported while considering health inequalities in systematic review, "there was no validated search filter for health inequalities", therefore it was difficult to search the databases using the exact terms. However, we used the this term based on those used in a Cochrane methodological review exploring how effects of health inequalities are assessed in SRs, ${ }^{76}$

\section{Conclusion}

The current systematic review highlighted that effective CCGs are essential to promote equality, improve health outcomes and reduce health inequalities. This study provides useful factors - enablers and barriers - to implement and deliver CC policy in improving health and wellbeing. These factors could be assessed in future monitoring/evaluation of local primary care services. Further research is needed to find the best methods and approaches in terms of developing objective measures and interventions to 
establish the link between clinical commissioning and health inequalities effectively, efficiently and equitably.

\section{Declarations}

\section{Declarations of interest: None}

\section{Funding:None}

Competing interests: None declared

Ethical approval: None sought

\section{Authors' contributions}

$\mathrm{KR}$ conceived and designed the study with the advice from OM; KR and OM reviewed, analysed and interpreted the data and contributed to drafting, revising and finalising the manuscript. All authors read and approved the final version of this manuscript.

\section{References}

1. Boyle S, European Observatory on Health Systems and Policies. United Kingdom (England): health system review. World Health Organization, Regional Office for Europe, 2011. https://apps.who.int/iris/handle/10665/330328. [accessed 8 April 2020].

2. Institute of Public Health. Commissioning for health and social care. London: Sage, 2014.

3. Smith JA, Curry N, Mays $\mathrm{N}$ et al. Where next for commissioning in the English NHS? London: Nuffield Trust, King's Fund, 2010.

4. Smith J, Mays N. GP led commissioning: time for a cool appraisal. BMJ. 2012; 344:e980. doi: 10.1136/bmj.e980.

5. Heginbotham C, Newbigging K. Commissioning health and wellbeing. London: Sage,London, 2014.

6. Smith J, Wistow G, Holder $\mathrm{H}$ et al. Evaluating the design and implementation of the whole systems integrated care programme in North West London: why commissioning proved (again) to be the weakest link. BMC Health Serv Res. 2019; 19: 228. https://doi.org/10.1186/s12913-019-4013-5

7. Bambra C, Gibson M, Sowden A et al. Tackling the wider social determinants of health and health inequalities: evidence from systematic reviews. J Epidemiol Community Health. 2010; 64: 284-291.

8. Asaria M, Ali S, Doran T et al. How a universal health system reduces inequalities lessons from England. J Epidemiol Community Health. 2016; 70:637-643.

9. Suhrcke M. The economic benefits of reducing health inequalities in England, 2009. http://www.instituteofhealthequity.org/resources-reports/fair-society-healthy-lives-themarmotreview/fair-society-healthy-lives-full-report-pdf.pdf. [accessed 7 April 2020]. 
10. Frontier Economics. Overall costs of health inequalities. Submission to the Marmot Review, 2009. http://www.instituteofhealthequity.org/resources-reports/fair-society-healthylives- the-marmotreview/fair-society-healthy-lives-full-report-pdf.pdf. [accessed 7 April 2020].

11. Marmot M. Fair society, healthy lives: The Marmot review. Strategies review of health inequalities post 2010, 2010. Available at: http://www.instituteofhealthequity.org/resourcesreports/ fair-societyhealthy-lives-the-marmot-review/fair-society-healthy-lives-full-reportpdf.pdf. [accessed 7 April 2020].

12. Department of Health. The NHS constitution. London: Department of Health, 2009.

13. UK Government. Health and Social Care Act, 2012. http://www.legislation.gov.uk/ukpga/2012/7/contents/enacted. [accessed 7 April 2020].

14. Guidance for NHS commissioners on equality and health inequalities legal duties. London: NHS, Equality and health inequalities unit, 2015.

15. Department of Health. Equity and excellence: Liberating the NHS. London: Department of Health, London, 2010.

16. Boseley S. NHS success in tackling health inequality varies hugely across England, 2016. https://www.theguardian.com/society/2016/aug/20/poor-healthcare-leading-to-hospitaladmissionsshows-no-social-divide. [accessed 7 April 2020].

17. Balkham A, Alderson S. The biggest car crash in the NHS history: the media portrayal of GP pay before and after the introduction of the Health and Social Care Bill 2011. Prim Health Care Res Dev. 2017; 18: 84-91.

18. Exworthy M, Blane D, Marmot M. Tackling health inequalities in the United Kingdom: the progress and pitfalls of policy. Health Serv Res. 2003; 38(6 Pt 2):1905-1922.

19. Exworthy M, Bindman A, Davies HU et al. Evidence into policy and practice? Measuring the progress of U.S. and U.K. policies to tackle disparities and inequalities in U.S. and U.K. health and health care. Milbank Q. 2006; 84:75-109.

20. Stewart J. The government of uncertainty. London: Institute for public policy and research, London, 1990.

21. Mannion R. General practitioner commissioning in the English national health service: continuity, change, and future challenges. Int J Health Serv. 2008; 38:717-730

22. Takundwa R, Jowett S, McLeoad H et al. The effects of environmental factors on the efficiency of clinical commissioning groups in England: a data environment analysis. J Med Syst. 2017; 41 : 97. doi: 10.1007/s10916-017-0740-5

23. Wenzl M, McCuskee S, Mossialos E. Commissioning for equity in the NHS: rhetoric and practice, $\mathrm{Br}$ Med Bull. 2015; 115: 5-17.

24. Porter A. David Cameron's NHS reforms are now a 'car crash', says Alan Milburn, 2011. The Telegraph. 15 June. https://www.telegraph.co.uk/news/politics/8578022/David-Camerons-NHSreforms-are-now-a-car-crash-says-Alan-Milburn.html. [accessed 7 April 2020] 
25. Oliver A, Mossialos E. Equity of access to health care: outlining the foundations for action. $J$ Epidemiol Community Health. 2004; 58:655-658.

26. Fleurbaey M, Schokkaert E. Equity in health and health care. In: Pauly MV, McGuire TG, Barros PP, editors. Handbook of health economics. Amsterdam: Elsevier, 2011; p.1003-1092.

27. Timmins N. Healthcare model set for radical shake-up. Financial Times. 15 August,2010. http://www.ft.com/cms/s/0/6e0d14e6-a88c-11df-86dd-00144feabdc0.html\#axzz32tkdJMRs. [accessed 7 April 2020]

28. Allin S, Grignon M, Le Grand J. Subjective unmet need and utilization of health care services in Canada: what are the equity implications? Soc Sci Med. 2010; 70:465-472.

29. Dixon M. Clinically led commissioning-joyous liberation or here we go again? J R Soc Med. 2012; 105: 217-220.

30. Antman E, Lau J, Kupelnick B et al. A comparison of results of meta-analyses of randomized control trials and recommendations of clinical experts: treatment for myocardial infarction. JAMA. 1992; 268:240-248.

31. Oxman A, Guyatt G. The science of reviewing research. Ann N Y Acad Sci. 1993; 703:125-133.

32. Higgins JPT, Green S. Cochrane handbook for systematic reviews of interventions. Chichester: Wiley, 2011.

33. Katcher BS. Medline: a guide to effective searching in PubMED \& other interfaces. San Francisco: The Ashbury Press, 2006.

34. Ayiku L, Levay P, Hudson T et al. The MEDLINE UK filter: development and validation of a geographic search filter to retrieve research about the UK from OVID MEDLINE. Health Info Libr J. 2017 34: 200216.

35. Moher D, Liberati A, Tetzlaff J et al. The PRISMA Group. Preferred reporting items for systematic reviews and meta-analyses: the PRISMA statement. PLoS Med. 2009; 6: e1000097. doi:10.1371/journal.pmed1000097.

36. Lockwood C, Munn Z, Porritt K. Qualitative research synthesis: methodological guidance for systematic reviewers utilizing meta-aggregation. Int J Evid Based Healthc. 2015; 13:179-187.

37. Munn Z, Moola S, Lisy K et al. Methodological guidance for systematic reviews of observational epidemiological studies reporting prevalence and incidence data. Int J Evid Based Healthc. 2015; 13:147-153

38. Hong QN, Pluye P, Fàbregues S et al. Mixed Methods Appraisal Tool (MMAT), version 2018. Registration of Copyright (\#1148552). Canadian Intellectual Property Office, Industry Canada, 2018.

39. Souto RQ, Khanassov V, Hong QN et al. Systematic mixed studies reviews: updating results on the reliability and efficiency of the mixed methods appraisal tool. Int J Nurs Stud. 2015; 52:500-501.

40. Pluye P. Mixed kinds of evidence: synthesis designs and critical appraisal for systematic mixed studies reviews including qualitative, quantitative and mixed methods studies. Evid Based Med. $2015 ; 20: 79$. 
41. Kerins $\mathrm{C}$, McSharry J, Hayes $\mathrm{C}$ et al. Barriers and facilitators to implementation of menu labelling interventions to support healthy food choices: a mixed methods systematic review protocol. Syst Rev. 2018; 7:88(2018). https://doi.org/10.1186/s13643-018-0752-3

42. Borenstein M, Hedges L, Higgins J et al. Introduction to meta- analysis. John Chichester: Wiley, 2009.

43. Centre for Reviews and Dissemination. Systematic Reviews CRD's guidance for undertaking reviews in health care. York: University of York, 2008.

44. Braun V, Clarke V. Using thematic analysis in psychology. Qual Res Psychol. 2006; 3: 77-101.

45. Joffe H. Thematic analysis. In: Harper D, Thompson A, editors. Qualitative methods in mental health and psychotherapy: a guide for students and practitioners. Wiley, Wiley: Chichester; 2012; p. 209223.

46. McDermott I, Checkland K, Moran V et al. Achieving integrated care through commissioning of primary care services in the English NHS. BMJ Open. 2019; 9:e027622. doi:10.1136/ bmjopen-2018027622

47. Turner D, Salway S, Mir G et al. Prospects for progress on health inequalities in England in the postprimary care trust era: professional views on challenges, risks and opportunities. BMC Public Health. 2013; 13:274. doi: 10.1186/1471-2458-13-274.

48. Cheetham M, Visram S, Rushmer R et al. 'It is not a quick fix' structural and contextual issues that affect implementation of integrated health and well-being services: a qualitative study from north east England. Public Health. 2017; 152:99-107.

49. Salway S, Mir G, Turner, D et al. Obstacles to "race equality" in the English national health service: insights from the healthcare commissioning arena. Soc Sci Med. 2016; 152:102-110.

50. Al-Haboubi $\mathrm{M}$, Klass $\mathrm{C}$, Jones $\mathrm{K}$ et al. Inequalities in the use of dental services among adults in inner South East London. Eur J Oral Sci. 2013; 121:176-181.

51. Gadsby EW, Peckham S, Coleman A et al. Commissioning for health improvement following the 2012 health and social care reforms in England: what has changed? BMC Public Health. 2017; 17:1-11. doi: 10.1186/s12889-017-4122-1.

52. Bull C. Localism plays to your strengths. Public Health Today; 2012 4-5.

53. Limb M. Patients will be involved in assessing CCGs, NHS England decides. BMJ. 2013; 347:f7165.

54. Øvretveit J. Purchasing for health: a multidisciplinary introduction to the theory and practice of health purchasing. Maidenhead: Open University Press, 1995.

55. Hammond J, Mason T, Sutton M et al. Exploring the impacts of the 2012 Health and Social Care Act reforms to commissioning on clinical activity in the English NHS: a mixed methods study of cervical screening. BMJ Open. 2019; 9(4), e024156.

56. Klasa K, Greer SL, van Ginneken E. Strategic purchasing in practice: comparing ten European countries. Health Policy. 2018; 122: 457-472.

57. Henry $\mathrm{H}$. New models of care and integrating services: commissioning, partnering and improving community wellbeing. Tackling health inequalities - devolution, integration and new models of care. 
Westminster Social Policy Forum Keynote Seminar. 15 November 2016. London: Westminster Social Policy Forum, 2016.

58. Westminster Social Policy Forum (2016) Tackling health inequalities - devolution, integration and new models of care, 2016. Westminster Social Policy Forum Keynote Seminar. 15 November 2016. London: Westminster Social Policy Forum, 2016.

59. Moran V Checkland K Coleman A et al. General practitioners' views of clinically led commissioning: cross-sectional survey in England. BMJ Open.2017; 7:e015464. doi:10.1136/bmjopen-2016-015464

60. Atkins L, Kelly MP, Littleford C et al. From the National Health Service to local government: perceptions of public health transition. Public Health. 2019; 174: 11-17.

61. Earwicker R. The impact of devolution on health inequalities - localising commissioning, service design and regional variation. Tackling health inequalities - devolution, integration and new models of care. Westminster Social Policy Forum Keynote Seminar. 15 November 2016. London: Westminster Social Policy Forum, 2016.

62. Marshall M, Holti R, Hartley J et al. GP leadership in clinical commissioning groups: a qualitative multi-case study approach across England. Br J Gen Pract. 2018; 68(671), e427-e432. DOI: https://doi.org/10.3399/bjgp18X696197.

63. Williamson D. New models of care and integrating services: commissioning, partnering and improving community wellbeing. Tackling health inequalities - devolution, integration and new models of care. Westminster Social Policy Forum Keynote Seminar. 15 November 2016. London: Westminster Social Policy Forum, 2016.

64. Checkland K, McDermott I, Coleman A et al. Complexity in the new NHS: longitudinal case studies of CCGs in England. BMJ Open. 2016; 6:e010199. doi:10.1136/bmjopen-2015-010199

65. Humphery T, Claver K. General practitioners' perceptions on their role in light of the NHS five year forward view: a qualitative study. London J Prim Care. 2018; 10:54-58.

66. Marks L, Cave S, Hunter DJ et al. Public health governance and primary care delivery: a triangulated study. Project Report. London: National Institute for Health Research, 2011.

67. Blaxter M. Key concepts: health. Cambridge Polity Press, 2010.

68. Iqbal Z. Is it important to take primary care seriously in readdressing health inequalities? Qual Prim Care. 2009; 17: 243-245.

69. Warwick-Giles L. An exploration of how clinical commissioning groups are tackling health inequalities. Dissertation. Manchester: University of Manchester, 2014.

70. Marmot M, Allen J, Boyce T et al. Health equity in England: The Marmot Review 10 years on. London: Institute of Health Equity, 2020.

71. McDermott I, Checkland K, Coleman A et al. Engaging GPs in commissioning: realist evaluation of the early experiences of Clinical Commissioning Groups in the English NHS. J Health Serv Res Policy. 2017; 22: 4-11.

72. Department of Health. Commissioning framework for health and well-being. London: $\mathrm{DH}, 2007$ 
73. Department of Health. NHS world class commissioning - competencies. London: DH, 2007.

74. NHS Improvement. An introduction to the NHS change model. London: NHS, 2016.

75. Maden M. Consideration of health inequalities in systematic reviews: a mapping review of guidance. Syst Rev. 2016; 28:202.

76. Welch $\mathrm{V}$, Tugwell P, Petticrew $\mathrm{M}$ et al. How effects of health equity are assessed in systematic reviews of interventions. Cochrane Database Syst Rev. doi: 10.1002/14651858.

\section{Additional Files}

Addition file 1: Systematic review protocol.

Addition file 2: Excluded studies.

\section{Figures}

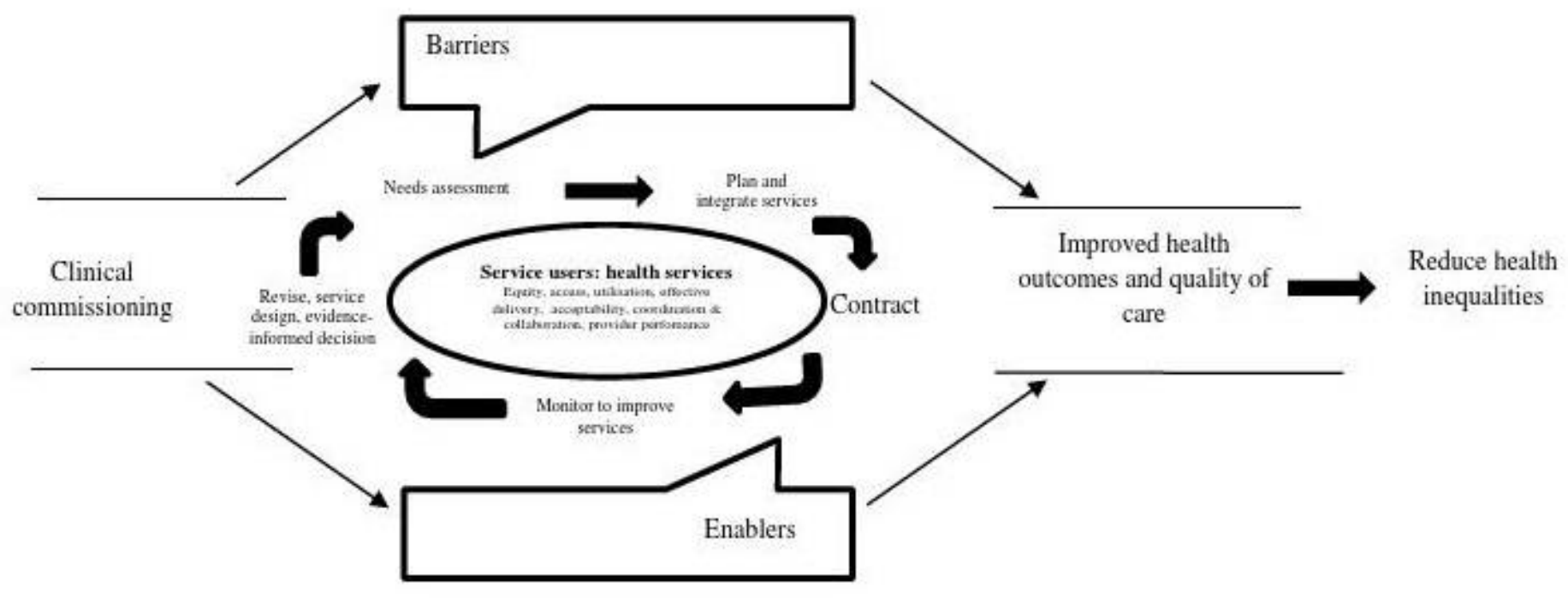

\section{Figure 1}

Conceptual framework of clinical commissioning and health inequalities 


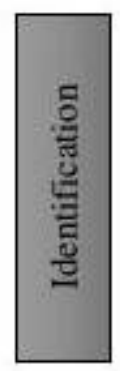

Records identified through database searches $(n=2166)$

(MEDLINE- 772, EMBASE -626, Allied \& Complementary Medicine- 11, DHDATA- 23, Global Health- 2, CINAHL- 724, PsycINFO- 8)
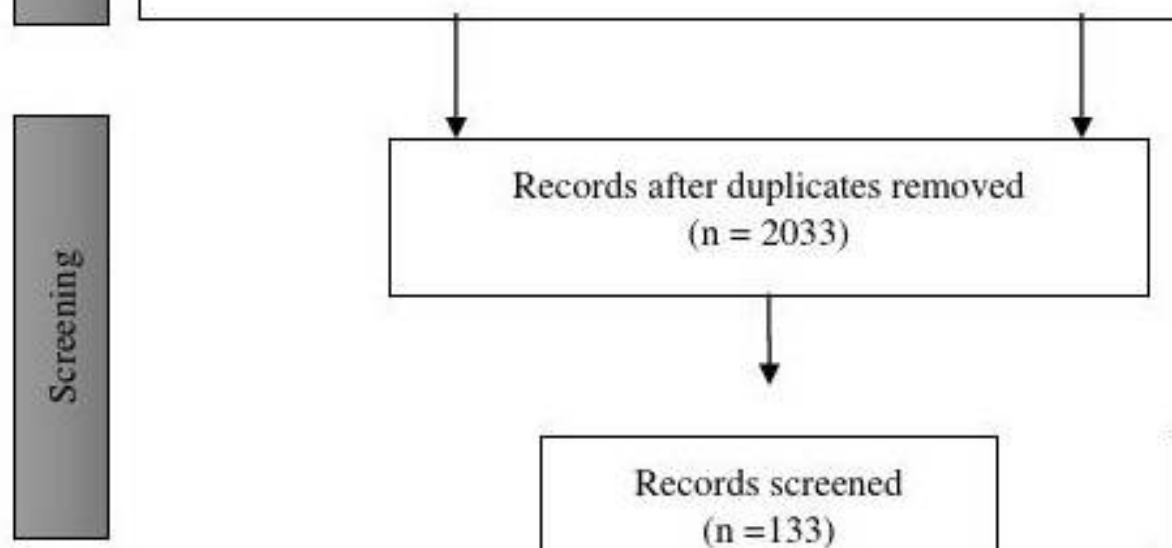

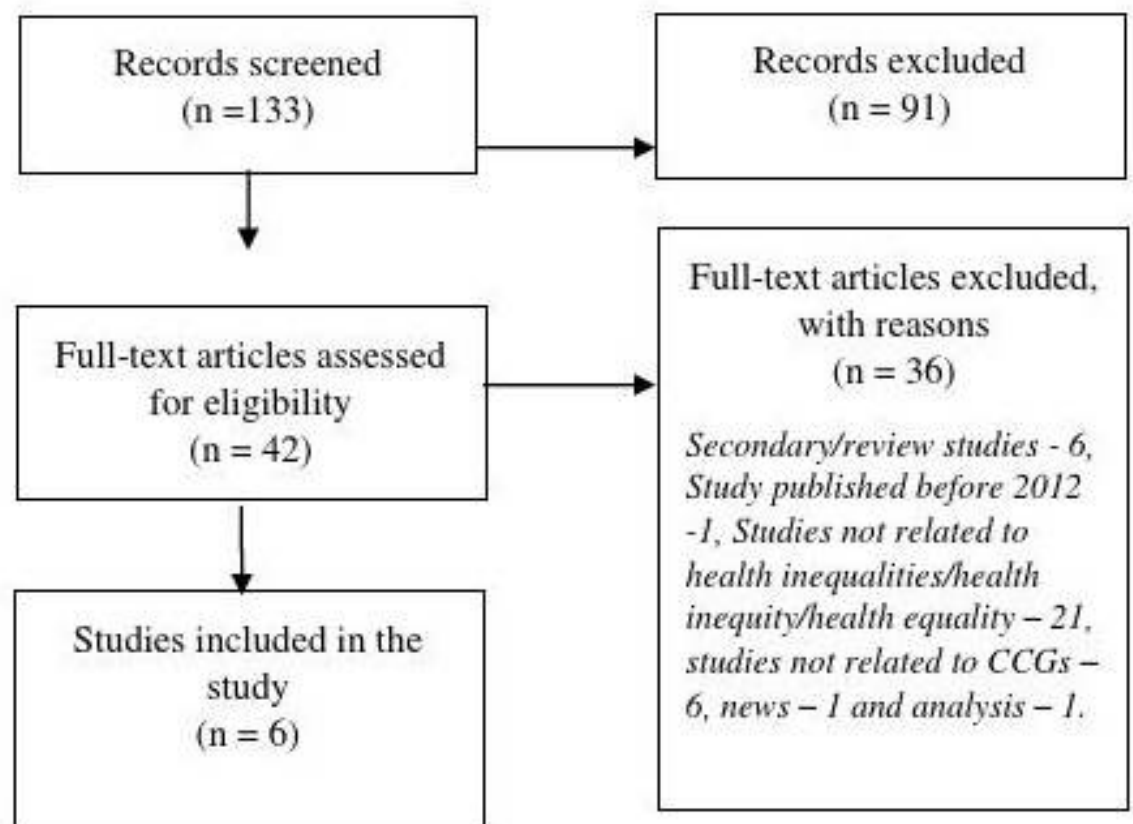

Figure 2

PRISMA Flow diagram to show results of searches

\section{Supplementary Files}

This is a list of supplementary files associated with this preprint. Click to download.

- Additionalfile1Studyprotocol.docx

- Additionalfile2Summaryofexcludedstudies.docx 